\title{
Interaction of dissolved and colloidal material during the mixing of different pulps
}

\section{Concepcion Monte*, Donald MacNeil, Carlos Negro and Angeles Blanco}

Chemical Engineering Department, Complutense University of Madrid, Madrid, Spain

* Corresponding author.

Chemical Engineering Department, Complutense University of Madrid, Avda. Complutense, s/n., 28040 Madrid, Spain

E-mail: cmonte@quim.ucm.es

\begin{abstract}
Mixtures of stickies-containing and stickies-free pulps were investigated for their deposition potential in an attempt to better understand the interactions of dissolved and colloidal material (DCM) when mixing two different pulps. The filtered pulp mixtures were tested in a deposition apparatus which measures both the dynamic fluid as well as impact deposition by an established optical scanning method. A pulp filtrate of model stickies led to deposition according to the proportion of stickies-containing pulp in the mixture. Other mixtures of pulps, however, led to deposition that differed from the predicted value. It is theorised that pulp fibres present in the mixture could adsorb the polysaccharides that would otherwise keep the colloidal system electrostatically stable. This destabilisation was most prominent at lower proportions of the stickies-free pulp suspensions used for mixing. These results show that care must be taken when mixing different pulps for paper and board production, as even a small amount of replacement pulp can lead to destabilisation of DCM and formation of deposits. Furthermore, special care must be taken when mixtures of pulps are used to validate stickies measurements.
\end{abstract}

Keywords: deposit formation; dissolved and colloidal material; papermaking; paper recycling; pulp mixtures; stickies.

\section{Introduction}

One of the main problems in the papermaking process is the accumulation of dissolved and colloidal material (DCM) in the white water system, which can be destabilised during the process and affect both the runnability of the machine and the product quality. DCM is introduced into the process with raw materials, recovered or virgin fibres, chemicals, and fresh water.

Recovered paper as raw material has many environmental and economic advantages. However, it can also cause serious drawbacks owing to the contaminants that are introduced in the system. A higher number of process chemicals (additives) are known for problem solution with this regard. These additives, by contrast, are also potential contaminants when they are reintroduced into the system with recycled paper or with reused water (Ricard and Dorris 2007a,b). From the well known paper contaminants (wet-strength agents, latex from coated paper, adhesives, ink binders of water based inks, etc.), the DCM fraction is particularly problematic because it cannot be removed by conventional processes (Blanco et al. 2001).

A potential problem is that such complex systems can be easily destabilised when new additives are introduced and parts of DCM are precipitated as stickies or tacky deposits (white pitch) (Monte et al. 2004). The deposits themselves can be composed of many different compounds, both organic and inorganic, including stickies, pitch compounds, and process aids originating from the DCM in process water (MacNeil et al. 2006; Miranda et al. 2008). High levels of these contaminants can also lead to impaired paper quality, and particularly to decreased paper strength and lower friction (Blanco et al. 2009).

The following detrimental effects can occur in the case of accumulation and destabilisation of DCM:

- Effects on machine productivity: lower retention and drainage, presence of deposits, scaling, breaks, cleaning downtime, etc.

- Effects on additive efficiency: optical aids, sizing agents, wet-end and dry strength additives, retention aids, etc.

- Effects on product quality: formation problems, lower optical properties, holes, spots, lower strength, lower printability performance, etc.

Destabilisation of DCM can occur owing to changes in process conditions, e.g., if electrolytes are introduced (Sundberg et al. 1996). But the removal of stabilising material can also be detrimental. Chemically pulped fibres can adsorb polysaccharides, which otherwise would keep the DCM stabilised, and thus leave a vulnerable system behind with a tendency to electrostatic agglomeration in the presence of calcium or other cations (Sundberg et al. 1994b).

By contrast, when deinked pulp (DIP) is mixed with thermomechanical pulp (TMP), it might be expected that the tendency to deposition is decreased. However, in some cases a mixture of DIP and TMP led to the opposite effect: the amount of deposition was increased owing to the synergy between pitch and microstickies, which destabilised each other (Castro and Dorris 2004; Haynes 2007, 2008; Banerjee and Haynes 2008; Banerjee et al. 2009).

Cationic demand can be taken as an indicator for the presence of detrimental substances in water samples coming from 
process waters of a paper mill. Most detrimental DCM is negatively charged and keeps the system electrostatically stable. This is the reason why the term "anionic trash" is usual. As long as the system is stable, deposition generally remains low. However, once the system is destabilised, DCM agglomerises and the precipitates can be adsorbed onto the fibres or onto the paper machine equipment.

Mill experience shows that it is not always possible to correlate the cationic demand of the white waters with the amounts of sticky deposits, because not all stickies are anionic. Therefore, this traditional measurement has to be complemented with, for example, deposition tests to predict problems at an industrial scale.

In this paper, the technique applied to determine the deposition of pulp mixtures was a deposition device previously developed by the Paper and Cellulose Group of the Chemical Department at Complutense University of Madrid (Blanco et al. 1998). Previous experiments (Blanco et al. 2000, 2001, 2007; Monte et al. 2004) demonstrated the usefulness of the deposition device. The apparatus is able to predict the potential contamination load of a given pulp, such as through cationic demand or turbidity measurements commonly used (Sundberg et al. 1993, 1994a,b,c; Johnsen et al. 2004). Moreover, the determination of deposition potential is possible, in which two different mechanisms are involved: (1) flow deposition, caused mainly by a destabilisation of colloidal material, and (2) impact deposition caused mainly by the physical tacky nature of the stickies.

The aim of this paper was to study the interaction of the DCM during mixture of different pulps by the measurement of the deposition tendency. The deposits should be measured by means of a deposition rotor and the amounts of deposits should be correlated with the cationic demand of the waters. Stability should be studied in four trials involving mixtures of a stickies-containing pulp and stickies-free pulp. Both laboratory pulps and real mill pulps will be studied.

\section{Materials and methods}

The characteristics of the pulps investigated are summarised in Table 1 .

\section{Stickies-containing pulp (SC) preparation}

Sample Label contained $20 \%$ of hydrodispersable adhesive, an acrylic-based adhesive. It was disintegrated according to ISO 52631 (2004) at a final consistency of $1.5 \%$, and further diluted with fresh water to a consistency of $1 \%$. The mill samples DIP-Tissue and DIP-NP were deinked pulps and tested at a consistency of $1 \%$. In the case of the DIP-Tissue sample, it was necessary to dilute it from $4.15 \%$ to $1 \%$ with fresh water.

The synthetic PSA sample was prepared from a mixture of copy and envelope papers contaminated with a mixture of eight different pressure sensitive adhesives according to the procedure of Doshi et al. (2003). The pressure sensitive adhesive mixture mainly consisted of 2-ethylhexyl acrylate, butylacrylate, butylacrylate with vinyl acetate copolymer, 2-ethylhexyl acrylate with vinyl acetate copolymer, a styrene butadiene rubber emulsion, and a styrene butadiene rubber hot melt. The sample was received at $1 \%$ consistency.

\section{Stickies-free pulp (SF) preparation}

Samples Label base, BKP and BSP were disintegrated according to ISO 5263-1 (2004) at a final consistency of $1.5 \%$, and further diluted with fresh water to a consistency of $1 \%$. Sample Copy paper was obtained from a mixture of clean copy and envelope papers in the same proportion according to the procedure by Doshi et al. (2003). The sample was received at $1 \%$ consistency.

\section{Mixture preparation}

The stickies-containing and stickies-free pulps, once prepared separately, were mixed at $25 \%$ incremental proportions. As the deposition methodology studies white water samples, the pulp mixtures were first filtered through a Dynamic Drainage Jar equipped with a 100-mesh wire to simulate the paper machine wire. The cationic demand of the resulting filtrate was measured before being added to the deposition tester (Figure 1). Each trial was carried out in triplicate simultaneously and the results shown are the average of three trials.

\section{Cationic demand measurement}

In all cases, the cationic demand of the waters was measured by colloidal titration. Instrument: automatic titrator Crison connected to a particle charge detector, Mütek PCD 03 (BTG), which determines the final point of the titration when the isoelectric point is reached. Polyethyleneimine was used as polymer with high molec-

Table 1 Mixtures of stickies-containing and stickies-free pulps.

\begin{tabular}{|c|c|c|c|c|}
\hline \multirow[b]{2}{*}{ Case } & \multicolumn{2}{|c|}{ Stickies-containing (SC) pulp } & \multicolumn{2}{|c|}{ Stickies-free (SF) pulp } \\
\hline & Name & Source & Name & Source \\
\hline 1 & Label & $\begin{array}{l}\text { Labels containing } 20 \% \text { of } \\
\text { hydrodispersable adhesive }\end{array}$ & $\begin{array}{l}\text { Label } \\
\text { base }\end{array}$ & Base paper of labels \\
\hline 2 & DIP-Tissue & $\begin{array}{l}\text { Machine chest of a German } \\
\text { deinking tissue paper } \\
\text { machine }(4.15 \%)\end{array}$ & BKP & Bleached kraft pulp \\
\hline 3 & DIP-NP & $\begin{array}{l}\text { Inlet of the second flotation } \\
\text { stage of a German deinking } \\
\text { newsprint paper machine }\end{array}$ & BSP & $\begin{array}{l}\text { Bleached beech } \\
\text { sulphite pulp }\end{array}$ \\
\hline 4 & PSA & $\begin{array}{l}\text { Copy and envelope paper } \\
\text { contaminated with a mixture } \\
\text { of different PSAs. Synthetic } \\
\text { pulp }\end{array}$ & $\begin{array}{l}\text { Copy } \\
\text { paper }\end{array}$ & Copy and envelope paper \\
\hline
\end{tabular}




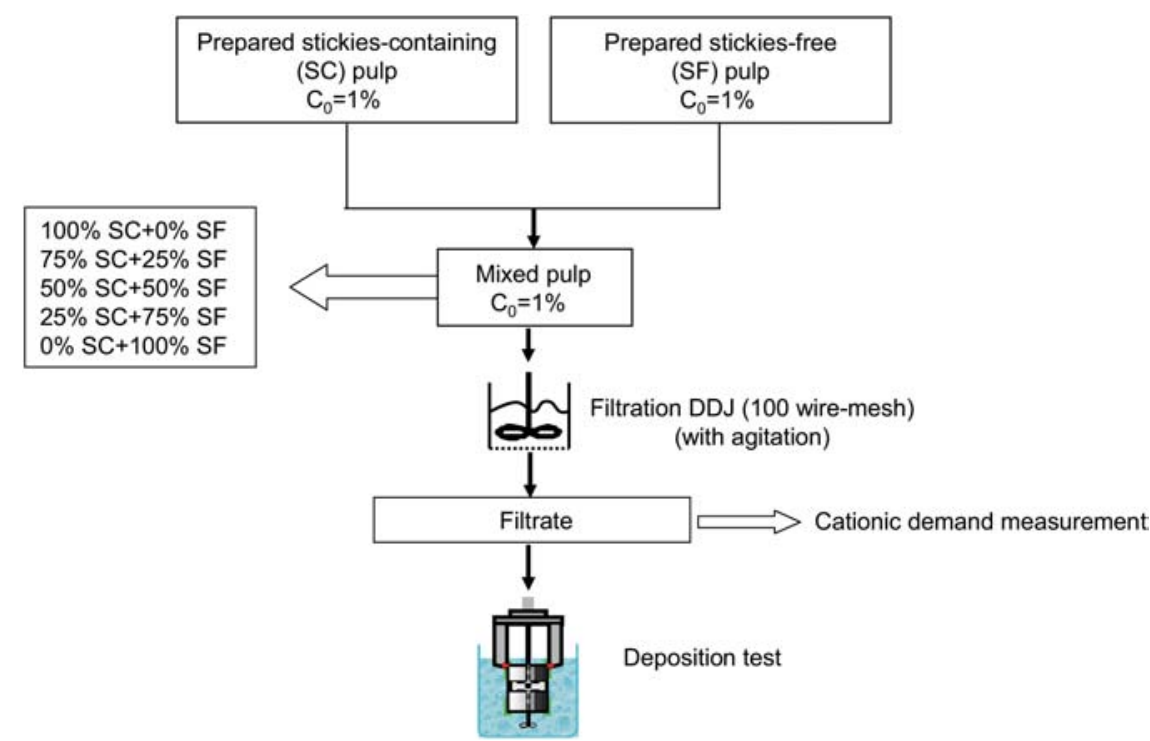

Figure 1 Mixture preparation and deposition procedure.

ular weight $\left(1.3 \times 10^{3}\right)$ and which has a medium to high cationic charge $\left(4.2 \mathrm{meq} \mathrm{g}^{-1}\right)$ (Polymin SK, BASF). The concentration of the polymer solution was approximately $0.0015 \mathrm{~N}$.

\section{Deposition test}

Deposition tests were carried out with the deposition tester as described in more detail in previous research (Sundberg et al. 1994b; Monte et al. 2004). It consists of a vertical cylindrical rotor assembly with open ends, collector plates lined with $0.05 \mathrm{~mm}$ thick stainless steel films, and an axial flow propeller. The propeller steers the liquid through the rotor assembly which directs the liquid toward the internal collector films which collect deposits by an impact mechanism. Simultaneously, the liquid passes the external plate which collects the deposits by a transference or by a dynamic-fluid (flow) mechanism.

Deposits were collected for $60 \mathrm{~min}$ while the temperature was kept constant at $50^{\circ} \mathrm{C}$ by immersion in a water bath. The stainless steel collectors were subsequently removed and dried before scanning with a commercial computer flatbed scanner (HP Scanjet $6100 \mathrm{C})$ at $600 \mathrm{dpi}$. The resulting scanned images were analysed using the image analysis system "Deposit Evaluation Software 1.2", also developed by the UCM Research Group (Figure 2). In this paper, the results are given separately as dynamic-fluid deposition, impact deposition, and the sum of the two, called total deposits. All are expressed in $\mathrm{mm}^{2}$, representing the deposition on the entire collector. The area of the internal films is approximately $50 \%$ of the area of the external collectors. When fines and fillers contained in the samples are attached to the deposit, they can be removed by washing (e.g., in the case of pitch studies). In this study, it was not necessary because inspection of the analysis images of the collectors revealed the presence of very little fines or fillers.

\section{Results and discussion}

\section{Case 1: Label+Label base}

An ideal model was prepared in the lab for one trial, where disintegrated labels were mixed with their respective disintegrated base paper. As seen in Figure 3, the filtered labels suspension had four times more deposition than the filtered base paper suspension. The deposition of the mixtures fol-

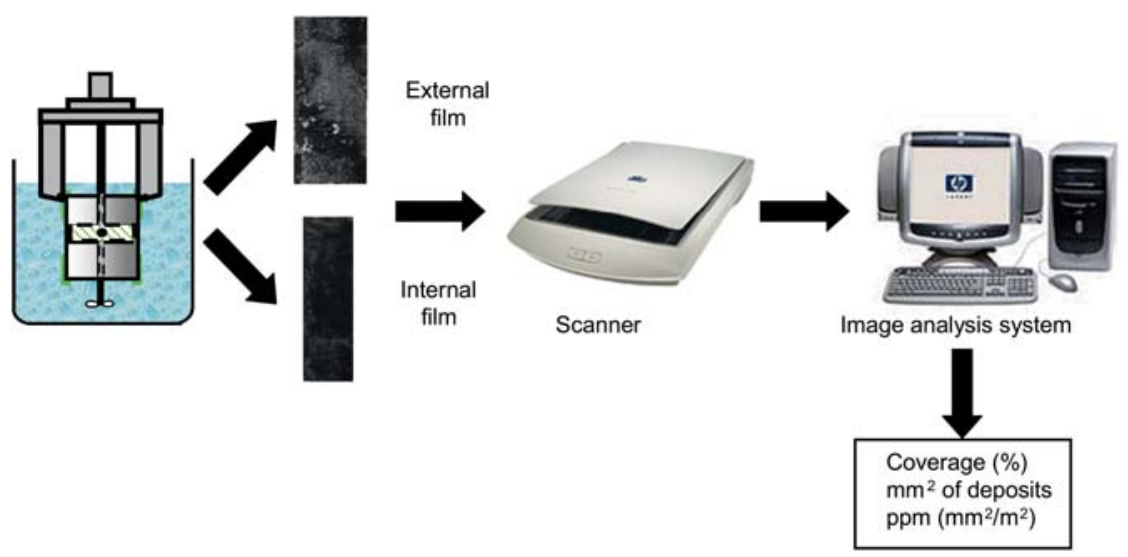

Figure 2 Deposition tester and deposition determination. 

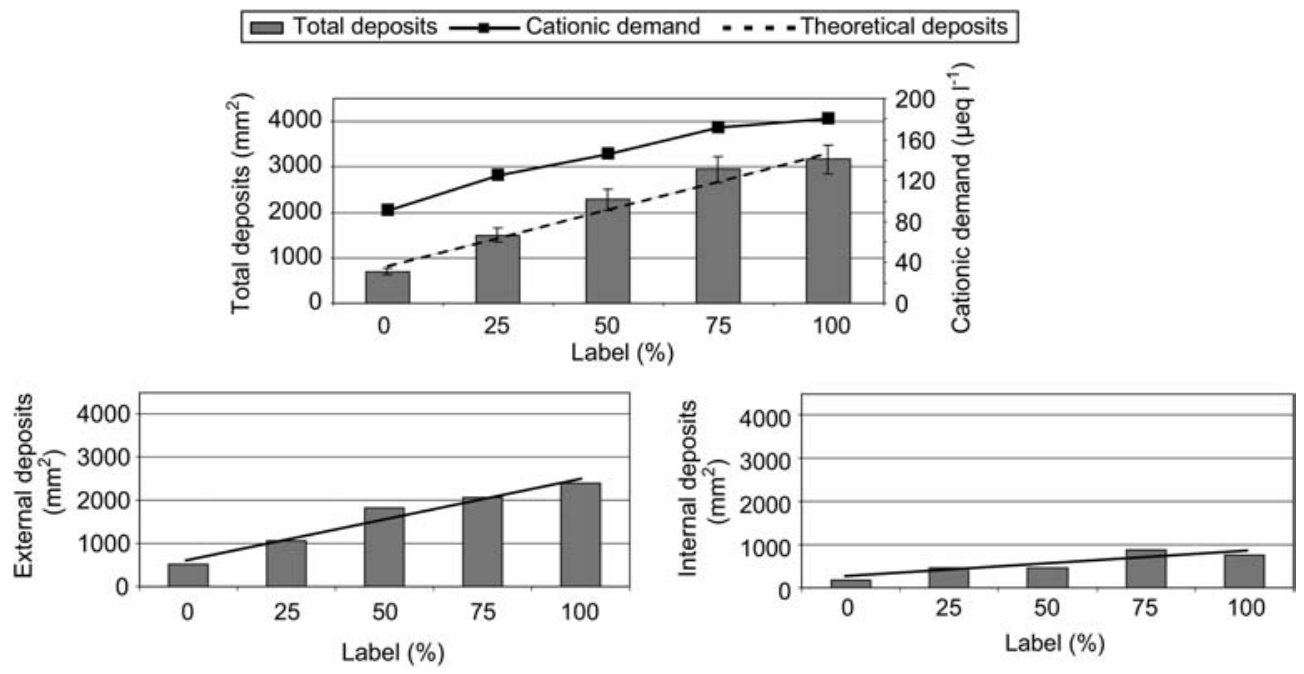

Figure 3 Deposition of Label/Label base mixtures.

lowed the deposition predicted by the stoichiometric ratios from the pure samples, as indicated by the dashed line in the figure. It appears that these model suspensions of stickies, without any accompanying DCM from other types of pulps, did not exhibit any interactive behaviour.

This holds for both the dynamic-fluid and impact depositions as well. It is also seen that the majority of the deposition originates from the dynamic-fluid deposition, even after taking into account the relative areas of the external and internal collector plates. The cationic demand for this trial is plotted on top of the deposition results. As visible, the deposition follows the cationic demand of the original mixture. For this case, cationic demand is obviously a good indicator of the potential deposition of the mixtures.

\section{Case 2: DIP-Tissue+BKP}

The content of depositable material in sample DIP-Tissue is slightly lower than the bleached kraft pulp (Figure 4). This could be as a result of the fact that the DIP pulp from the machine chest contains chemical additives such as wet strength agents and coagulants used as anionic trash catchers, which could keep the system stabilised and help diminishing deposition. The deposition occurred was close to the predicted or theoretical value for all mixture ratios with the exception of a small increase in the sample containing $25 \%$ tissue.

However, unlike in Case 1, the cationic demand did not reflect the trend in deposition, which actually decreased with increasing cationic demand. In this case, cationic demand is not a good indicator of the deposition potential, neither for pure samples nor for mixtures.

\section{Case 3: DIP-NP+BSP}

Figure 5 shows that the DIP-NP filtrate produced over four times more deposition than the BSP-filtrate, owing to the higher concentration of DCM (e.g., adhesives, binders, wood

\section{Total deposits $\longrightarrow-$ Cationic demand $\ldots-$ - Theoretical deposits}
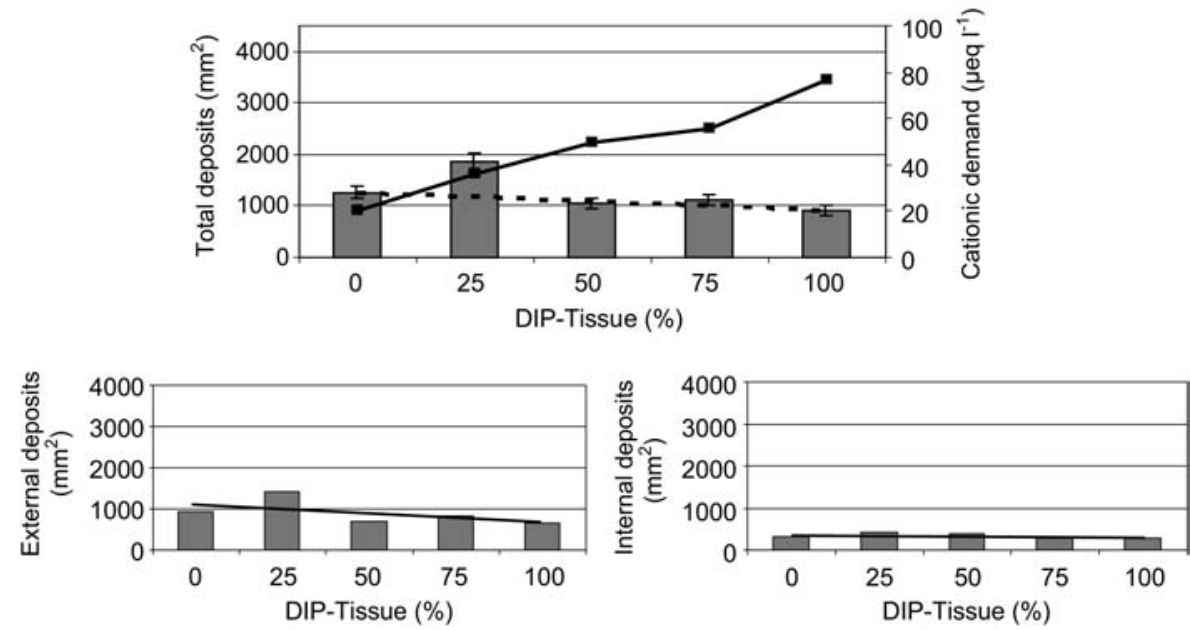

Figure 4 Deposition of DIP-Tissue/BKP mixtures. 

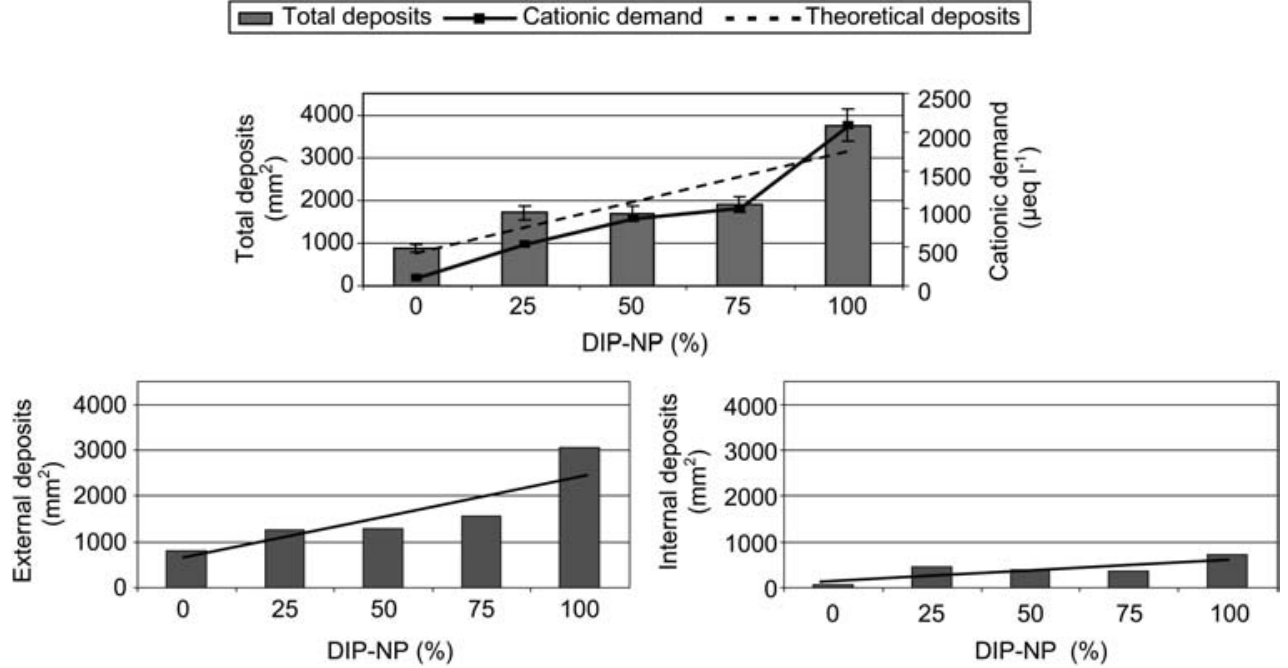

Figure 5 Deposition of DIP-NP/BSP mixtures.

extractives and deinking chemicals). The impact deposition for the $100 \%$ BSP sample was negligible, but the flow deposition was surprising. In this trial, the dynamic-fluid type depositions are 3 to 4 times higher than those of the impact deposition type. It should be noted that the deposition is not an accumulation of just tacky materials, but other materials could contribute to the deposits.

The mixtures of the two samples did not fit exactly to the predicted value, as indicated by the broken line on the top, if the pulp filtrates would form deposits related to their respective proportions in the mixed filtrate. There was a drop in deposition measured on the films when BSP-filtrate accounted for $25 \%$ and $50 \%$ of the total.

Interestingly, it appears that the introduction of chemical fibres or the respective DCM has either stabilised or destabilised this system. Sundberg et al. (1994b) showed that chemical fibres can absorb polysaccharides, removing a stabilising component from the system. Some of the remaining DCM then precipitates or deposits on paper machine equipment. Probably, similar reactions took place in this trial: the adsorbed and removed polysaccharides led to precipitation of the formerly dissolved materials. These were filtrated and the filtrate contained less potential depositable materials. Consequently, the deposition decreased for those mixtures. This interpretation also provides an account for the drop in cationic demand after filtration but before the deposition test. Anionic trash has obviously been removed from the system. In such cases, cationic demand is a good indicator of deposit problems.

\section{Case 4: PSA+Copy paper}

In this trial, two nearly identical samples were mixed, except one sample was artificially contaminated with a mixture of PSAs. This does not mean that the "stickies-free" pulp did not have any deposition potential, as there are binders in the paper and even adhesives in the envelopes. That is reflected in the results (Figure 6) which showed the largest amounts of deposition for any pure pulp samples observed in this study. However, interestingly enough, the PSA-contaminated pulp had no significant additional amount of deposition than the non-contaminated pulp. In fact, when looking at the impact deposition results, the PSA-contaminated pulp resulted in less deposition which was not expected. The lack of difference in cationic demand between the two samples is also remarkable. Apparently, the added PSA contributed very little to the total anionic trash.

As in Case 3, additions of the stickies-free pulp led to less deposition than expected, and less than either of the pulp filtrates on their own. The same destabilisation could have caused these results, and even to a greater degree. The difference between dynamic-fluid deposition and impact deposition is strengthening this interpretation. A non-linear deposition trend is evident for the former but not for the latter. This is in line with the underlying theory of destabilisation phenomena according to the dynamic-flow and impact deposition mechanisms. In Figure 5 (Case 3), the same pattern is seen, albeit to a less pronounced degree.

Unlike Case 3, the cationic demand is not affected by destabilisation, probably as a result of the non-ionic character of the detrimental substances from the adhesive mixture. However, as previously seen, the presence of PSAs did not affect the initial cationic demand of the filtrate water, and therefore its precipitation would not affect the overall cationic demand in the filtrate. In conclusion, cationic demand does not successfully indicate the deposition potential of these pulps.

\section{Conclusions}

The mixture of pulps leads to interactions which affect the amount of deposition on metal surfaces, particularly at low concentrations of a stickies-free pulp. In the case of hydrodispersable adhesives, an increase in deposition is directly and linearly related to the proportion of adhesives in the mixture. However, when non-hydrodispersable adhesives or real DIP mill samples are studied, unusual deposit trends are 

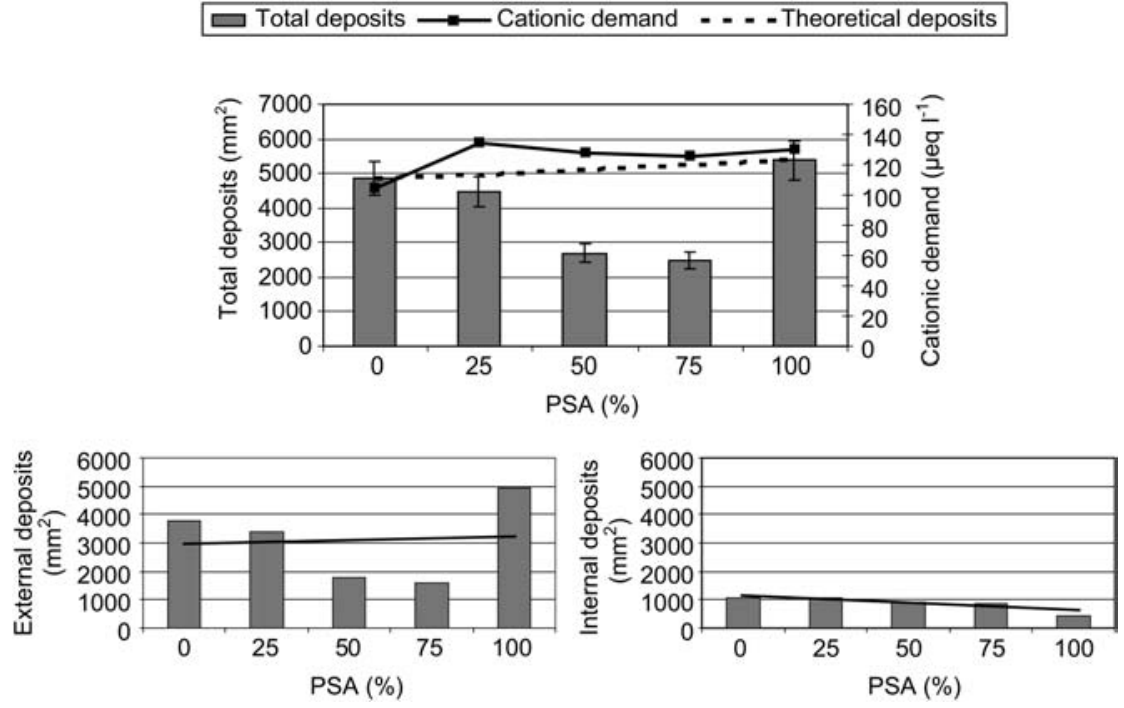

Figure 6 Deposition of PSA/Copy paper mixture.

observed. Two cases demonstrated a decrease in deposition for some mixture ratios. For the DIP-NP-BSP and the PSACopy paper mixtures, dilutions of $25 \%$ and $50 \%$ stickies-free pulp produced up to half of the predicted deposition, probably as a result of the DCM interaction with the polysaccharides that remains with the fibre fraction. Cationic demand determination is not always an accurate measure of deposition potential, as deposition not only depends on the absolute concentration of certain compounds but also on their interactions. Care must be taken in terms of sticky predictions in production processes when various pulps are mixed or when mixtures of pulps are used to validate stickies measurements.

\section{Acknowledgements}

The authors wish to acknowledge the financial support to the Community of Madrid for the Project PROLIPAPEL-CM (S-0505/AMB/ 0100), to the Ministry of Science and Innovation for the Project CTM2008-06886-C02-01, and to the European Union for the AQUAFIT Project (Ref. 211534).

\section{References}

Banerjee, S., Haynes, R.D. (2008) Stickies control with cyclodextrins. Tappi J. 7:4-7.

Banerjee, S., Yang, R., Haynes, R.D. (2009) Aggregation of colloidal material in recycling process water. Tappi J. 8:19-23.

Blanco, A., Garcia, J., Monte, M.C., Negro, C., Tijero, T. (1998) Equipment for the deposition of adherent matter contained in a suspension. European Patent Application PCT/ES98/00029 (WO 98/39079.11.09.1998).

Blanco, A., Negro, C., Monte, M.C., Otero, D., Tijero, J. (2000) New system to predict deposits due to DCM destabilization in paper mills. Pulp Pap. Canada 101:40-43.

Blanco, A., Negro, C., Monte, M.C., Otero, D., Tijero, J. (2001) Destabilization of dissolved and colloidal material derived from coated paper. Appita J. 54:132-135.
Blanco, A., Miranda, R., Negro, C., García-Súarez, C., García-Prol, M., Sánchez, A. (2007) Full characterisation of stickies in a newsprint mill: the need for a complementary approach. Tappi J. 6:19-25.

Blanco, A., Negro, C., Diaz, L., Saarimaa, V., Sundberg, A., Holmbom, B. (2009) Influence of thermostable lipase treatment of thermomechanical pulp (TMP) on extractives and paper properties. Appita J. 62:113-117.

Castro, C., Dorris, G.M. (2004) Measuring microstickies deposition by monitoring pressure drop through a collector. Prog. Pap. Recycling 13:23-33.

Doshi, M.R., Blanco, A., Negro, C., Delagoutte, T., Dorris, G.M., Castro, C.C., Hamman, A., Haynes, R.D., Houtman, C., Scallon, K., Putz, H.J., Johansson, H., Venditti, R.A., Copeland, K., Chang, H.M. (2003) Comparison of microstickies measurement methods. Part I: sample preparation and measurement methods. Prog. Pap. Rec. 12:35-42.

Haynes, R.D. (2007) Establishing the techniques to relate paper machine issues to colloidal microstickies. Prog. Pap. Recycling 16:14-26.

Haynes, D. (2008) Understanding and controlling colloidal organics when mixing TMP and DIP. In: TAPPI Engineering, Pulping and Environmental Conference, Portland, Oregon, USA, 24-28 August 2008.

ISO 5263-1:2004: “Pulps-Laboratory disintegration. Part 1: Disintegration of chemical pulps".

Johnsen, I., Lenes, M., Magnusson, L. (2004) Stabilization of colloidal wood resin by dissolved material from TMP and DIP. Nord. Pulp Pap. Res. J. 19:22-28.

MacNeil, D., Sarja, T., Messmer, M., Reunanen, M., Niinimäki, J. (2006) Analysis of stickies in deinked pulp. Part II: distribution of stickies in deinked pulp. Prof. Papermaking 1:10-14.

Miranda, R., Balea, A., Sanchez de la Blanca, E., Carrillo, I., Blanco A. (2008) Identification of recalcitrant stickies and their sources in newsprint production. Ind. Eng. Chem. Res. 47:6239-6250.

Monte, M.C., Blanco, A., Negro, C., Tijero, J. (2004) Development of a methodology to predict sticky deposits due to the destabilisation of dissolved and colloidal material in papermaking application to different systems. Chem. Eng. J. 105:21-29.

Ricard, M., Dorris, G. (2007a) Recirculation contaminates whitewater solids. Part I: supernatant and fines isolation and characterization. In: 93rd Annual Meeting Preprints - Book B. Pulp 
and Paper Technical Association of Canada, Montreal, QC, Canada, 5-9 February 2007. B251-262.

Ricard, M., Dorris, G. (2007b) Recirculation contaminates whitewater solids. Part II: contamination of fines and fillers by extractives and metals. In: 93rd Annual Meeting Preprints - Book B. Pulp and Paper Technical Association of Canada, Montreal, QC, Canada, 5-9 February 2007. B263-270.

Sundberg, A., Ekman, R., Holmbom, B., Sundberg, K., Thornton, J. (1993) Interactions between dissolved and colloidal substances and a cationic fixing agent in mechanical pulp suspensions. Nord. Pulp Pap. Res. J. 8:226-231.

Sundberg, A., Ekman, R., Holmbom, B., Grönfors, H. (1994a) Interactions of cationic polymers with components in thermomechanical pulp suspensions. Pap. Puu 76:593.
Sundberg, K., Thornton, J., Ekman, R., Holmbom, B. (1994b) Interactions between simple electrolytes and dissolved and colloidal substances in mechanical pulp. Nord. Pulp Pap. Res. J. 9:125-128.

Sundberg, K., Thornton, J., Pettersson, C., Holmbom, B., Ekman, R. (1994c) Calcium induced aggregation of dissolved and colloidal substances in mechanical pulp suspensions. J. Pulp Pap. Sci. 20:J317-J321.

Sundberg, K., Thornton, J., Holmbom, B., Ekman, R. (1996) Effect of wood polysaccharides on the stability of colloidal wood resin. J. Pulp Pap. Sci. 22:J226-J230.

Received August 1, 2009. Accepted November 11, 2009.

Previously published online February 10, 2010. 